\title{
Dehydrocostus lactone inhibits in vitro gastrinoma cancer cell growth through apoptosis induction, sub-G1 cell cycle arrest, DNA damage and loss of mitochondrial membrane potential
}

Hou-yong Long ${ }^{1}$, Qing-xian Huang ${ }^{2}$, Yong-yang Yu³, Zhen-bin Zhang ${ }^{2}$, Zeng-wu Yao², Hong-bing Chen², Jun-wei Feng ${ }^{4}$

\author{
${ }^{1}$ Department of General Surgery, Shandong Jining No. 1 People's Hospital, Shandong, \\ China \\ 2Department of Gastroenterology, Yantai Yuhuangding Hospital, Medical College \\ of Qingdao University, Shandong, China \\ ${ }^{3}$ Department of General Surgery, Laishan Second People's Hospital, Yantai, \\ Shandong Province, China \\ ${ }^{4}$ Department of Surgical Oncology, Tangshan Worker's Hospital, Tangshan, China
}

Submitted: 14 November 2016

Accepted: 16 February 2017

Arch Med Sci 2019; 15 (3): 765-773

DOI: https://doi.org/10.5114/aoms.2018.73128

Copyright @ 2018 Termedia \& Banach

\section{Abstract}

Introduction: The purpose of the present study was to evaluate the antiproliferative activity of dehydrocostus lactone against human BON-1 cancer cell lines and to explore the possible underlying mechanism.

Material and methods: MTT cell viability assay was used to determine cytotoxic effects of dehydrocostus lactone in BON-1 cells. Fluorescence and transmission electron microscopic (TEM) techniques were used to study the effect of the compound on cellular morphology and apoptosis. Flow cytometry was used to assess the effect on cell cycle phase distribution. Effects of the drug on cell apoptosis and mitochondrial membrane potential were analyzed by flow cytometry using annexin $v$ and rhodamine-123 as fluorescent probes.

Results: The results of the present study indicated that dehydrocostus lactone significantly $(p<0.01)$ inhibited the growth of BON-1 cancer cells. These growth inhibitory effects of dehydrocostus lactone on BON-1 were found to be time and concentration-dependent. The IC 50 of dehydrocostus lactone were found to be $71.9 \mu \mathrm{M}$ and $52.3 \mu \mathrm{M}$ at 24 and $48 \mathrm{~h}$ time intervals respectively. The growth inhibitory effects of dehydrocostus lactone were found to be due to loss of mitochondrial membrane potential, the induction of apoptosis and sub-G1 cell cycle arrest.

Conclusions: Dehydrocostus inhibits in vitro gastrinoma cancer cell growth and therefore may prove beneficial in the management of gastrinoma cancer.

Key words: dehydrocostus lactone, pancreatic neuroendocrine tumor, cell cycle, apoptosis.

\section{Introduction}

Gastrinoma arises as a result of a tumor in the duodenum or pancreas which secretes surplus amounts of gastrin, leading to ulcers in the stomach or duodenum. Gastrinoma mostly originates in the pancreas but

\author{
Corresponding author: \\ Dr. Jun-wei Feng \\ Department of \\ Surgical Oncology \\ Tangshan Worker's \\ Hospital \\ 27 Wenhua Road \\ 063000 Tangshan, China \\ Phone/fax: +8603152821821 \\ E-mail: fengjunwei39@ \\ hotmail.com
}


can also be found in the duodenum or stomach Pancreatic gastrinoma is characterized by a higher tendency to be malignant. Gastrin is a hormone that controls the amount of acid in the stomach. Gastrinomas produce enormous amounts of gastrin, and this causes the stomach to make more acid. Gastrinomas are a type of neuroendocrine tumors that develop in cells that are triggered by nerve cells to produce hormones. Gastrinomas are also known as pancreatic neuroendocrine tumors. Pancreatic neuroendocrine tumors (PNETs) are malignant tumors likely arising from islet cells of the pancreas [1, 2]. Pancreatic neuroendocrine tumors secrete a range of hormones including insulin, glucagon and somatostatin. However, several PNETs do not secrete any hormone [3]. Pancreatic neuroendocrine tumors can be very difficult to treat and can vary from benign to highly malignant. PNETs can be slow growing or aggressive in certain cases.

Regarding PNET treatment, surgical resection alone is mostly useful for its cure in initial stages. However, in most PNET cases (about 50\%) patients have an advanced stage of the disease and then suffer from uncontrolled hormone secretion giving rise to many other complications [4]. It has been reported that gastrinoma tumors show a good response towards the use of cytotoxic chemotherapeutic drugs especially the combination of cisplatin and etoposide $[5,6]$. However, there are serious side-effects associated with these cytotoxic anticancer drugs. Hence, there is a need to find alternative chemotherapeutic agents for the treatment of gastrinoma tumors. The objective of the present study was to evaluate the anticancer and apoptotic effects of dehydrocostus usually isolated from Cichorium intybus in the BON-1 PNET cell line and to explore the possible underlying mechanism.

\section{Material and methods}

\section{Chemicals and other reagents used in this study}

Dehydrocostus lactone (> 98\%) was purchased from Chengdu Preferred Biotech Co. Ltd (China) and was dissolved in dimethyl sulfoxide (DMSO) at the concentration of $50 \mathrm{mM}$, stored as small aliquots at $-20^{\circ} \mathrm{C}$. Different concentrations of the compound were prepared $(0,5,25,50,75$ and $100 \mu \mathrm{M})$ for cell culture experiments. 3-[4,5-dimethyl-2-thiazolyl]-2,5-diphenyl tetrazolium bromide (MTT) was purchased from Molecular Probes (USA). Dulbecco's modified Eagle's medium, fetal bovine serum (FBS), penicillin-streptomycin and rhodamine-123 (Rh-123) were obtained from Hangzhou Sijiqing Biological Products Co., Ltd, China. Propidium iodide (PI), trypsin, dimethyl sulfoxide (DMSO) and Hoechst 33258 were purchased from Sigma-Aldrich (USA).

\section{Cell line and culture conditions}

The human pancreatic neuroendocrine tumor cell line (BON-1) was procured from the Cancer Research Institute of Beijing, China. The cells were grown in DMEM supplemented with $10 \%$ fetal calf serum (FBS) and $150 \mathrm{U} / \mathrm{ml}$ of penicillin. Incubation of the cells was done at $37^{\circ} \mathrm{C}$ in a humidified atmosphere of $5 \% \mathrm{CO}_{2}$ and $95 \%$ air. The medium was stored at low temperature $\left(2-5^{\circ} \mathrm{C}\right)$. The medium was replaced every 2 days. Cells were subcultured every 4 days.

\section{Cell viability evaluation by MTT assay}

The cytotoxic effects of dehydrocostus lactone on BON-1 cell proliferation were determined by MTT assays. BON-1 cells $\left(2 \times 10^{5}\right.$ cells/well) were seeded and cultured with varying doses of dehydrocostus lactone $(0,5,25,75$, and $100 \mu \mathrm{M}$ each) for 24 and $48 \mathrm{~h}$. Following drug treatment, the medium was changed and 3-(4,5-dimethylthiazol-zyl)-2,5-diphenyltetrazolium bromide (MTT: $2 \mathrm{mg} / \mathrm{ml}$ ) was added for $3 \mathrm{~h}$. The number of viable cells is equal to the formation of formazan crystals which were dissolved in ethanol and the optical density was measured on a microplate reader (ELX 800; Bio-tek Instruments, Inc., Winooski, VT, USA) at a wavelength of $490 \mathrm{~nm}$. The effects of dehydrocostus lactone on cell viability were calculated as an inhibition ratio (I \%) using the following equation (optical density at $490 \mathrm{~nm}$ ):

$$
\mathrm{I} \%=\frac{\left[\mathrm{OD}_{490}(\text { Control })-\mathrm{OD}_{490}(\text { Treated })\right]}{\left[\mathrm{OD}_{490}(\text { Control })\right]} \times 100 \%
$$

\section{Detection of apoptosis using fluorescence microscopy}

BON- 1 cells $\left(2 \times 10^{5}\right.$ cells/well $)$ were plated in six-well plates and then cultured for $24 \mathrm{~h}$ to allow complete attachment to the surface of the plates. The cells were treated with various doses of dehydrocostus lactone treatment $(0,5,50$ and $100 \mu \mathrm{M})$ for $48 \mathrm{~h}$ and then stained with Hoechst $33258(2 \mu \mathrm{g} / \mathrm{ml})$ at $37^{\circ} \mathrm{C}$ for $20 \mathrm{~min}$. Nuclear morphology was examined under a fluorescence microscope (Olympus, Tokyo, Japan) to identify cells undergoing apoptosis.

\section{Ultrastructural analysis by transmission electron microscope (TEM)}

BON-1 cells were treated with or without dehydrocostus lactone for $48 \mathrm{~h}$ and fixed in sodium cacodylate $(\mathrm{pH}$ 7.4) and glutaraldehyde solution for $3 \mathrm{~h}$. The cells were washed in PBS, then fixed in 
$1.5 \% \mathrm{OsO}_{4}$ solution for $1 \mathrm{~h}$ at $25 \mathrm{C}$, washed and then dehydrated in an ethanol solution of increasing polarity ( $50 \%$ to $80 \%$ with 15 min of each bath). The cells were then embedded in EMbed 812 resin (SPI Supplies, PA, USA). After staining with uranyl acetate and lead citrate for $30 \mathrm{~min}$, cell ultrastructure was analyzed (at $300 \mathrm{kV}$ voltage) using ultra-thin sections with a transmission electron microscope (Hitachi High Technologies America, North 28th Avenue, Texas, United States).

\section{DNA fragmentation analysis}

BON-1 cells were seeded in a $100-\mathrm{mm}$ cell culture dish for $48 \mathrm{~h}$ and treated with 0, 5, 50 and $100 \mu \mathrm{M}$ dehydrocostus lactone for $48 \mathrm{~h}$. The cells were harvested and washed with PBS, and the pellets were lysed with a $200 \mu \mathrm{l}$ DNA lysis buffer (20 mM EDTA, 40 mM Tris-HCl) for 20 min. After centrifugation, the supernatants were prepared in an equal volume of $3 \%$ sodium-dodecyl sulfate, incubated with $3 \mathrm{mg} / \mathrm{ml}$ RNase $\mathrm{A}$ at $55^{\circ} \mathrm{C}$ for $3 \mathrm{~h}$ followed by digestion with $2.5 \mathrm{mg} / \mathrm{ml}$ proteinase $\mathrm{K}$ for $2 \mathrm{~h}$ at $20^{\circ} \mathrm{C}$. Subsequent to the addition of $10 \mathrm{M}$ ammonium acetate, the DNA was precipitated with cold ethanol and collected by centrifugation at $15,000 \times \mathrm{g}$ for $15 \mathrm{~min}$. DNA was then dissolved in gel loading buffer, separated by electrophoresis in $1.5 \%$ agarose gel and visualized under UV light, following ethidium bromide staining.

\section{Measurement of mitochondrial membrane potential $(\Lambda \Psi \mathrm{m})$}

Mitochondrial membrane potential (MMP) in the human pancreatic neuroendocrine tumor cell line (BON-1) was measured with rhodamine-123 dye, which preferentially enters the active mitochondria based on the highly negative MMP. The cells were seeded in 96-well plates at a density of $1 \times 10^{5}$ cells $/ \mathrm{ml}$. The cells were treated with varying doses of dehydrocostus lactone $(0,5,50$ and $100 \mu \mathrm{M})$. Depolarization of MMP results in the loss of rhodamine 123 from mitochondria and a decrease in intracellular fluorescence is observed. Rhodamine 123 (final concentration of $10 \mu \mathrm{M}$ ) was added to the harvested cells and analyzed using a FACSCalibur instrument (BD Biosciences, San Jose, CA, USA) equipped with Cell Quest 3.3 software.

\section{Cell cycle analysis}

The effect of dehydrocostus lactone on cell cycle phase distribution was evaluated by flow cytometry using propidium iodide as a probe. BON-1 cells $\left(2 \times 10^{5}\right.$ cells $\left./ \mathrm{ml}\right)$ were seeded in 60-mm dishes and treated with 0, 5, 50 and $100 \mu \mathrm{M}$ of dehydrocostus lactone for $48 \mathrm{~h}$. After treatment, the cells were trypsinized and washed twice with PBS. After that the cells were fixed with $70 \%$ cold ethanol overnight and then treated with $20 \mu \mathrm{g} / \mathrm{ml}$ RNase A, then stained with $3 \mu \mathrm{g} / \mathrm{ml}$ of propidium iodide. Finally the DNA content and cell cycle distribution were analyzed by flow cytometry. The experiments were repeated three times. The cell cycle analysis was performed by a FACSCalibur instrument (BD Biosciences, San Jose, CA, USA), equipped with Cell Quest 3.3 software with DNA propidium iodide $(\mathrm{PI})$ staining.

\section{Statistical analysis}

Data are presented as the mean \pm SEM of the control. All experiments were repeated at least three times. The differences between groups were analyzed by one-way ANOVA with Tukey's post hoc tests. Significance of difference was indicated as ${ }^{*} p<0.05,{ }^{* *} p<0.01$.

\section{Results}

\section{Antiproliferative effect of dehydrocostus lactone on the cytotoxicity of human pancreatic neuroendocrine tumor cell lines (BON-1)}

Figure 1 shows that the dehydrocostus lactone (Figure 2) exhibited dose-dependent as well as time-dependent growth inhibitory effects in these cells. The efficacy of the compound was evaluated by determining its $\mathrm{IC}_{50}$ value, which was found to be $71.9 \mu \mathrm{M}$ and $52.3 \mu \mathrm{M}$ at 24 and $48 \mathrm{~h}$ time intervals respectively.

\section{Apoptotic effects of dehydrocostus lactone in BON-1 cells}

After treating BON-1 cells with $0,5,50$ and $100 \mu \mathrm{M}$ doses of the compound, the cells revealed apoptotic morphological features including nuclear fragmentation and condensation, cellular

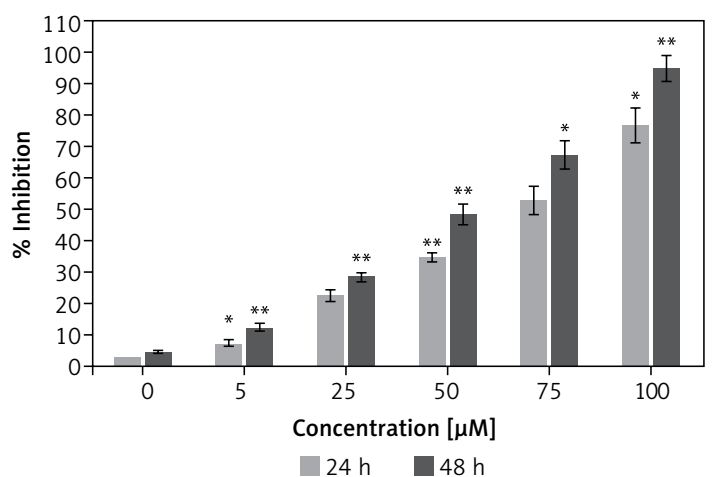

Figure 1. Cytotoxic effect of dehydrocostus lactone in human pancreatic neuroendocrine tumor cell lines (BON-1)

Data are shown as the mean $\pm S D$ of three independent experiments. ${ }^{*} p<0.05,{ }^{* *} p<0.01$, vs. $0 \mu \mathrm{M}$ (control). 


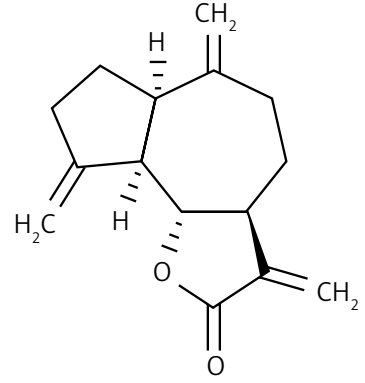

Figure 2. Chemical structure of dehydrocostus lactone

shrinkage, membrane blebbing, etc. In the untreated control group (Figure $3 \mathrm{~A}$ ), most of the cells showed regular morphology and homogeneous growth and were confluent. However, after treating cells with 5, 50 and $100 \mu \mathrm{M}$ doses of dehydrocostus lactone, apoptotic features described above began to appear and the effect intensified
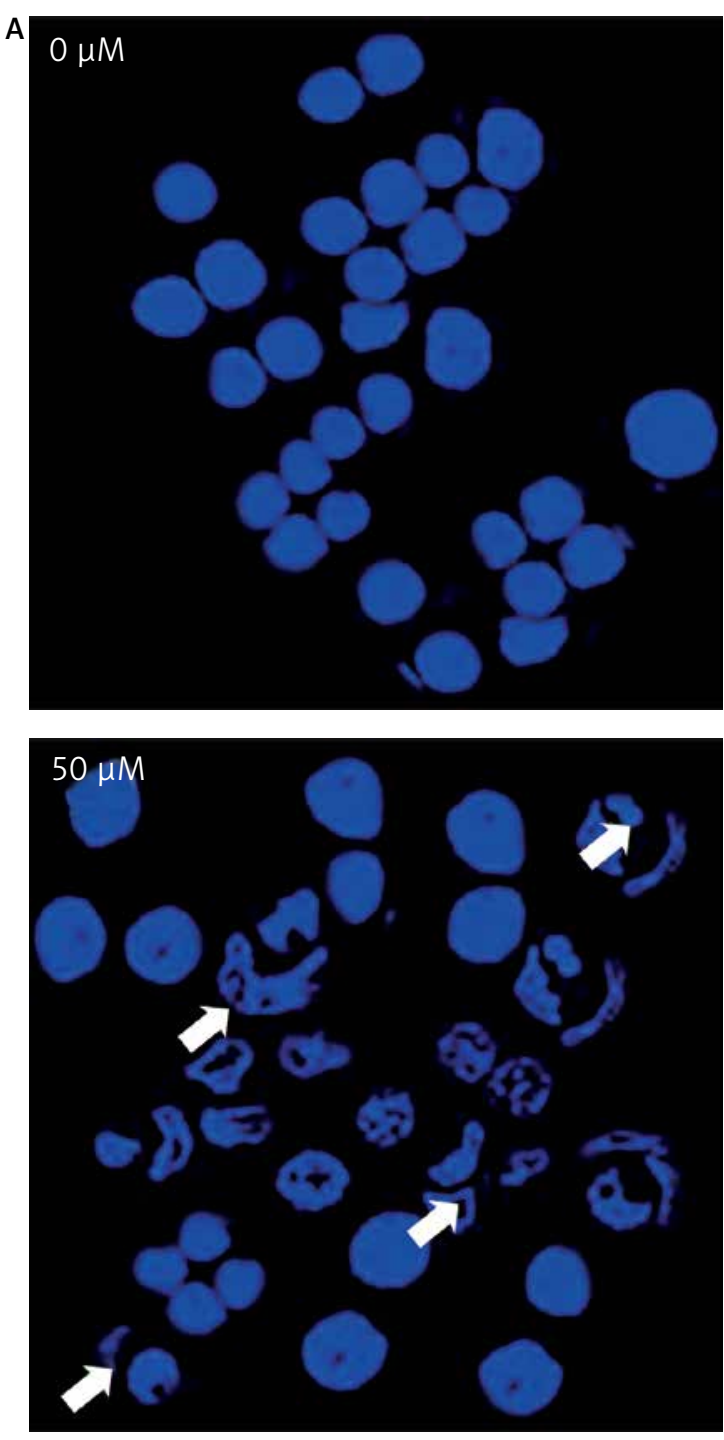

Figure 3. Apoptotic effect of indicated doses on dehydrocostus lactone in human pancreatic neuroendocrine tumor cell lines (BON-1). A - Fluorescence microscopy using Hoechst 33258 was carried out on treated and untreated cells. Apoptotic effect of indicated doses on dehydrocostus lactone in human pancreatic neuroendocrine tumor cell lines (BON-1). with increasing doses (Figure $3 \mathrm{~A}$ ). The results were further confirmed by $\mathrm{Pl} /$ annexin staining, which revealed that apoptotic cell populations in creased from 6.79 at $5 \mu \mathrm{M}$ to $48.5 \%$ at $100 \mu \mathrm{M}$ (Figure 3 B).

\section{Ultrastructural analysis of cellular apoptosis by transmission electron microscopy}

The fact that dehydrocostus lactone induces apoptosis in BON-1 cancer cells was further confirmed by using TEM. The results of this observation are shown in Figures 4 A-D. Control cells (untreated cells) exhibited normal ultrastructure with round nuclear membrane, normal mitochondria and the nucleolus present within the nucleus (Figure 4 A). But, after the cells were treated with 5, 50 and $100 \mu \mathrm{M}$ concentrations of dehydrocostus lactone for $48 \mathrm{~h}$, the mitochondria were destroyed,
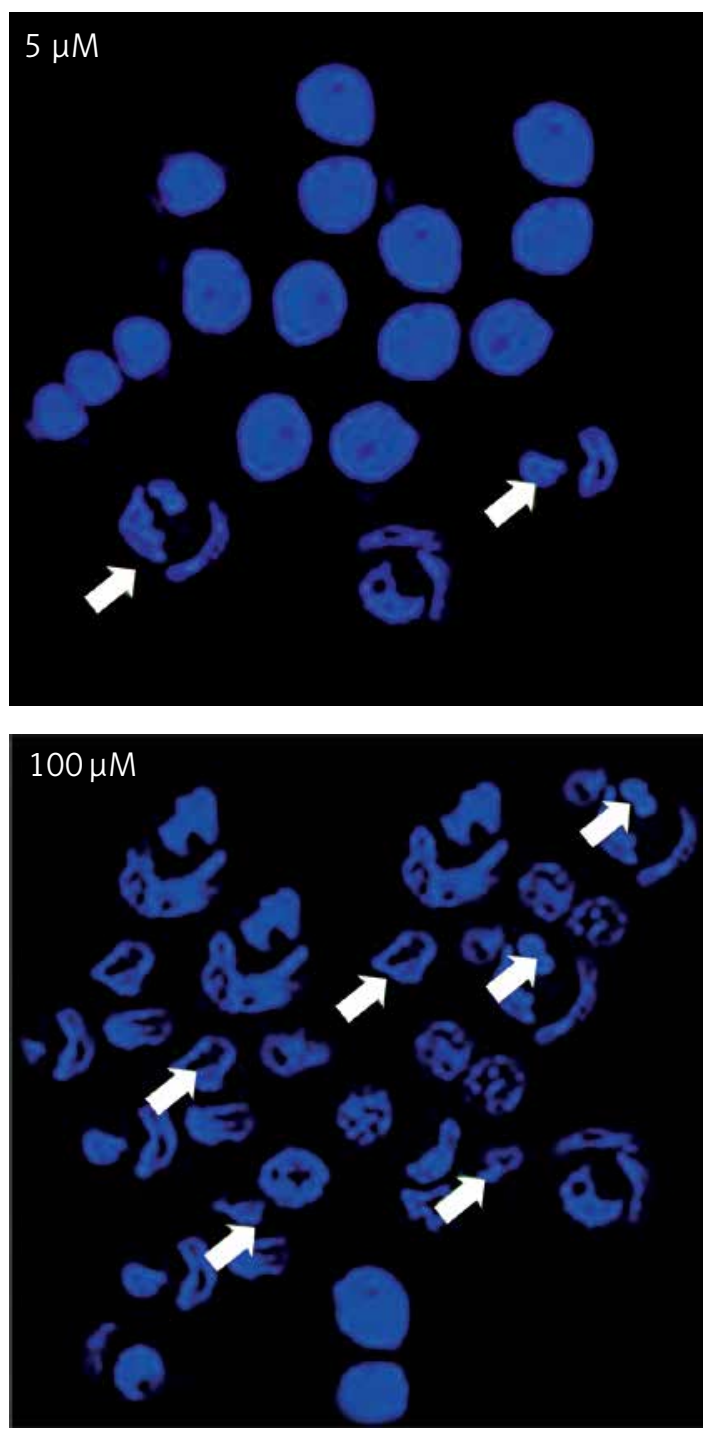

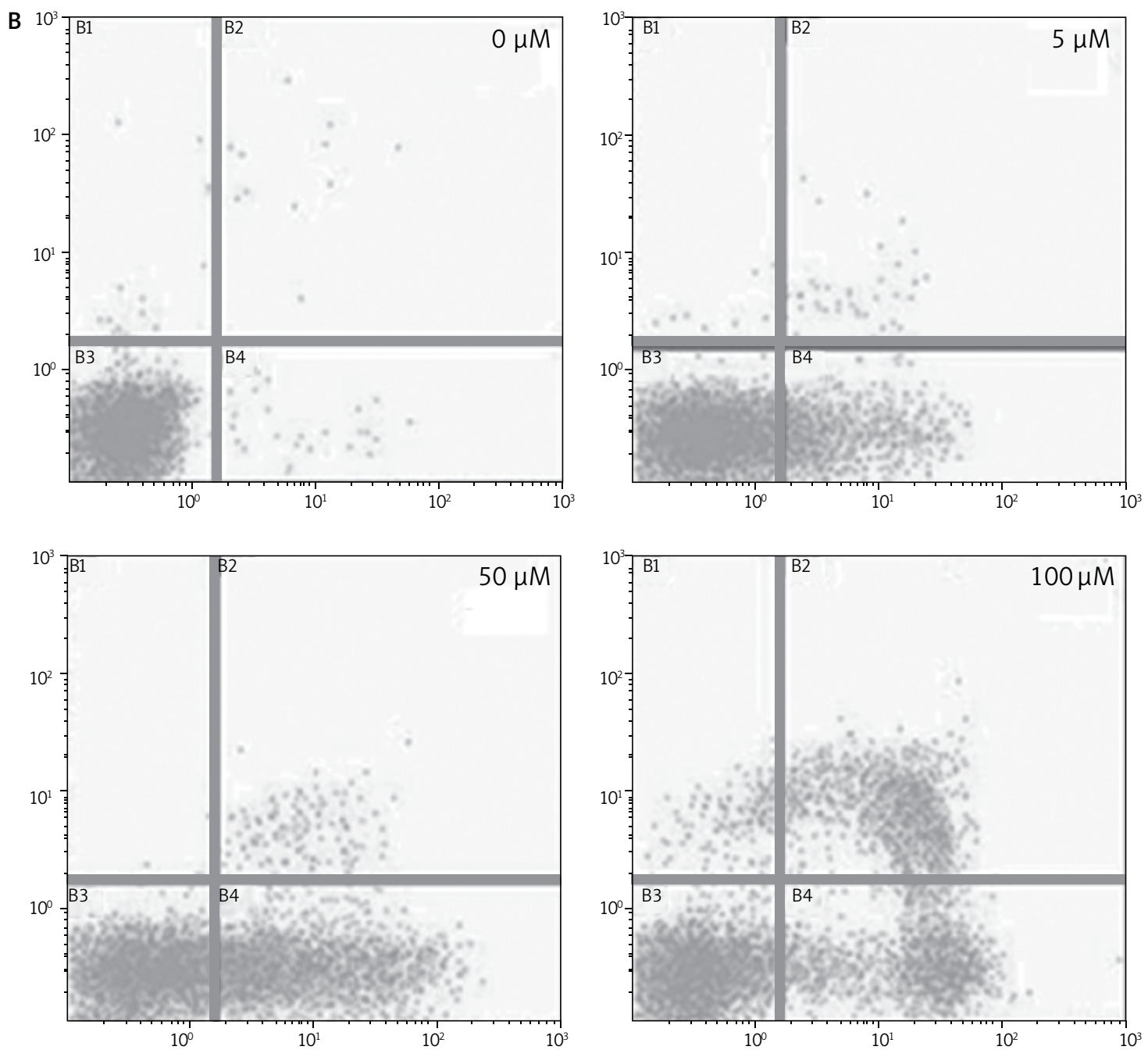

Figure 3. B - Annexin Pl/annexin $\mathrm{V}$ staining analyzed by flow cytometry. All images are representatives of three biological replicates

chromatin condensation occurred and the nuclear membrane disappeared. This was accompanied by the appearance of vacuoles in the cytoplasm, which is a hallmark of early apoptotic events which was clearly absent in untreated control cells (Figures 4 B-D). Thus TEM results confirm the results of fluorescence microscopy, which indicates that dehydrocostus lactone induces apoptosis in BON-1 cancer cells.

\section{Dehydrocostus lactone induces DNA fragmentation in BON-1 cells}

DNA fragmentation analysis induced by different doses of dehydrocostus lactone was observed by the formation of a DNA ladder using $1.5 \%$ agarose gel electrophoresis. DNA ladder formation was consistent with increasing doses of the compound, but no such DNA laddering was visible in the control group (Figure 5). However, increasing doses of the compound for $48 \mathrm{~h}$ led to a significant increase in DNA fragmentation. The DNA fragmentation is a sign of the apoptotic process which starts within the cell, further confirming that the dehydrocostus lactone induced cell death via apoptosis.

\section{Dehydrocostus lactone induced mitochondrial membrane potential loss ( $\Lambda \Psi \mathrm{m}$ loss)}

Loss of mitochondrial transmembrane potential is a crucial step in the intrinsic apoptotic event. In this study, we evaluated the effect of dehydrocostus lactone on the mitochondrial membrane potential loss in BON-1 cells using a fluorescent probe, Rh-123 and flow cytometric analysis. After the drug treatment, a significant increase in cells with decreased membrane potential was seen after $48 \mathrm{~h}$ (Figures $6 \mathrm{~A}-\mathrm{D}$ ). The fraction of cells with decreased $\Lambda \Psi \mathrm{m}$ seemed to follow the concentration of the compound. The percentage of cells with decreased $\Lambda \Psi \mathrm{m}$ increased from $3.58 \%$ in the control group to $14.2 \%, 24.6 \%$ and $43.3 \%$ in 5,50 and $100 \mu \mathrm{M}$-dehydrocostus lactone treated cells respectively. In cells, loss of $\Lambda \Psi \mathrm{m}$ leads to mem- 

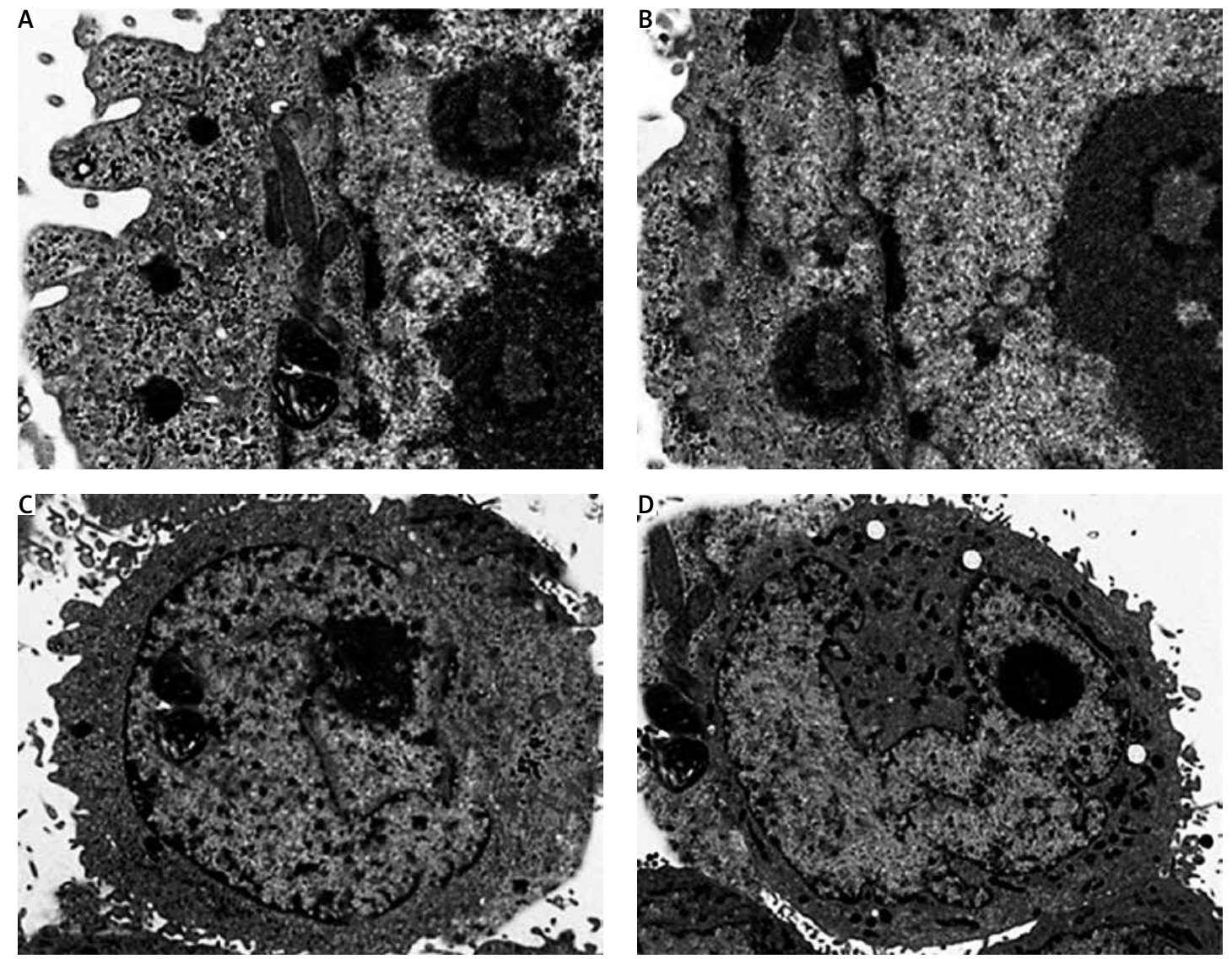

Figure 4. Transmission electron microscopy (TEM) analysis for evaluating the effect of dehydrocostus lactone on the apoptosis induction in BON-1 cells. A - Untreated control group, B-D -cells treated with 5, 50 and $100 \mu \mathrm{M}$ dose of the compound (cells were observed at $8000 \times$ magnification). Appearance of vacuoles at higher doses is a sign of an early apoptotic event. All images are representatives of three biological replicates

brane rupture followed by cytochrome c release and pro-apoptotic factors.

Dehydrocostus lactone induces sub-G1 cell cycle arrest in BON-1 cells

Figure 7 indicates that the compound increased the percentage of sub-G1 cells from $8.1 \%$ in the untreated group to $14.6 \%, 28.5 \%$ and $56.9 \%$ in groups treated with 5,50 and $100 \mu \mathrm{M}$ doses of dehydrocostus lactone respectively. The percentage of sub-G1 cells is an indication of the apoptotic cells which arise as a result of the treatment with the drug.

\section{Discussion}

Gastrinoma is a very lethal type of cancer and is very difficult treat like, many other types of cancers. Moreover, treatment options for gastrinoma are limited and are often associated with numerous side effects [1]. The findings of this study indicate that dehydrocostus lactone is a potent cytotoxic agent which induces significant growth inhibitory effects in human pancreatic neuroendocrine tumor cell lines (BON-1) in a time-dependent as well as dose-dependent manner. Our studies are also consistent with previous studies wherein sesquiterpene lactones have been reported to exhibit anticancer activities against a range of cancer types [7]. It has also been reported that these lactones exhibit selective cytotoxic activity against cancer cells and exhibit high $\mathrm{IC}_{50}$ values for normal cell lines indicating lower cytotoxicity for normal cells [8]. Moreover, to evaluate the effect of the solvent, we determined the cytotoxic effects of DMSO on BON-1 and the results indicated that DMSO had negligible antiproliferative effects (Figure 8). Fluorescence microscopy using Hoechst 33258 showed that the compound induced apoptotic morphological features in these cells characterized by nuclear fragmentation and condensation, cellular shrinkage, membrane blebbing, etc. Further, transmission electron microscopy indicated that dehydrocostus lactone treatment at increasing doses led to formation of vacuoles, disappearance of nuclear membrane and damaged mitochondria. The effect intensified with increased doses of the compound. The untreated cells, however, showed normal cellular morphology with round nuclei and intact mitochondria. Fur- 
ther, using $1.5 \%$ agarose gel electrophoresis, DNA fragmentation analysis induced by dehydrocostus lactone was carried out. The results of this experiment indicated that as compared to the untreated control which did not show any signs of DNA fragmentation, dehydrocostus lactone treated cells at increasing doses indicated significant levels of DNA fragmentation. Consistent with this, several studies have reported induction of apoptosis by dehydrocostus lactone and costunolide in many types of cancer cells [7-9].

Dehydrocostus lactone also induced significant loss of mitochondrial membrane potential $(\Lambda \Psi \mathrm{m}$ loss) in these cells. The percentage of cells with decreased $\Lambda \Psi \mathrm{m}$ seemed to follow the compound dose. The percentage of cells with decreased $\Lambda \Psi \mathrm{m}$ increased from $3.58 \%$ in the control group to $14.2 \%, 24.6 \%$ and $43.3 \%$ in 5, 50 and $100 \mu \mathrm{M}$-dehydrocostus lactone treated cells respectively. In cells, loss of $\Lambda \Psi \mathrm{m}$ leads to membrane rupture followed by cytochrome c release and pro-apoptotic factors. Loss of mitochondrial transmembrane potential is a crucial step in the intrinsic apoptotic event $[10,11]$. This compound also led to sub-G1 cell cycle arrest in BON-1 cells, the percentage of sub-G1 cells increasing from $8.1 \%$ in the untreated group to $14.6 \%, 28.5 \%$ and $56.9 \%$ in groups treated with 5,50 and $100 \mu \mathrm{M}$ doses of dehydrocostus lactone respectively.
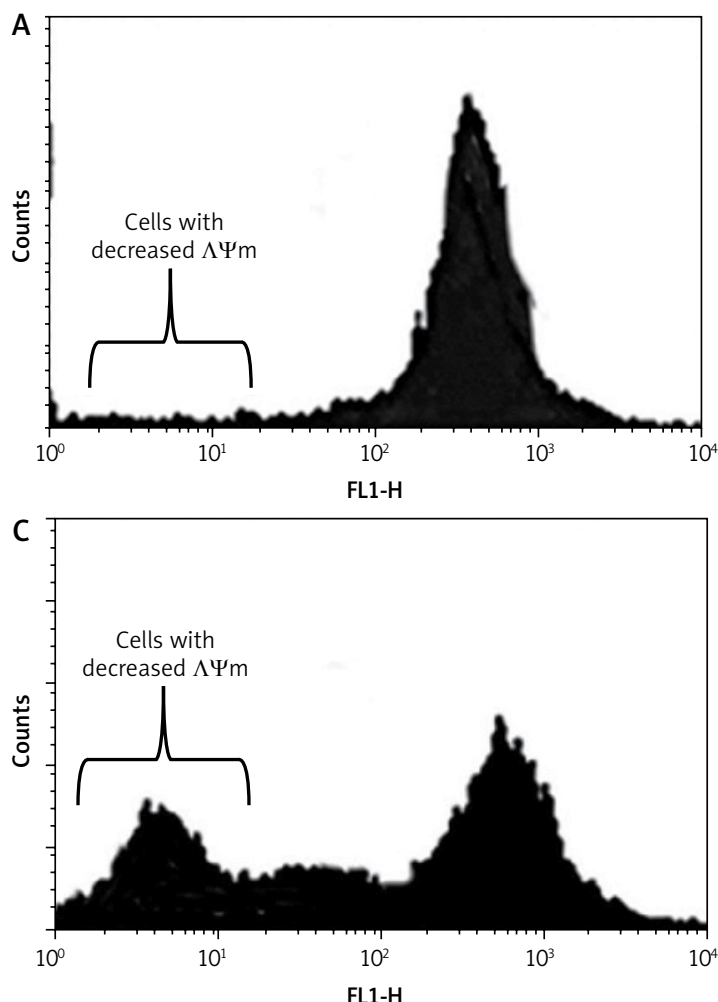

Dehydrocostus lactone dose $[\mu \mathrm{M}]$

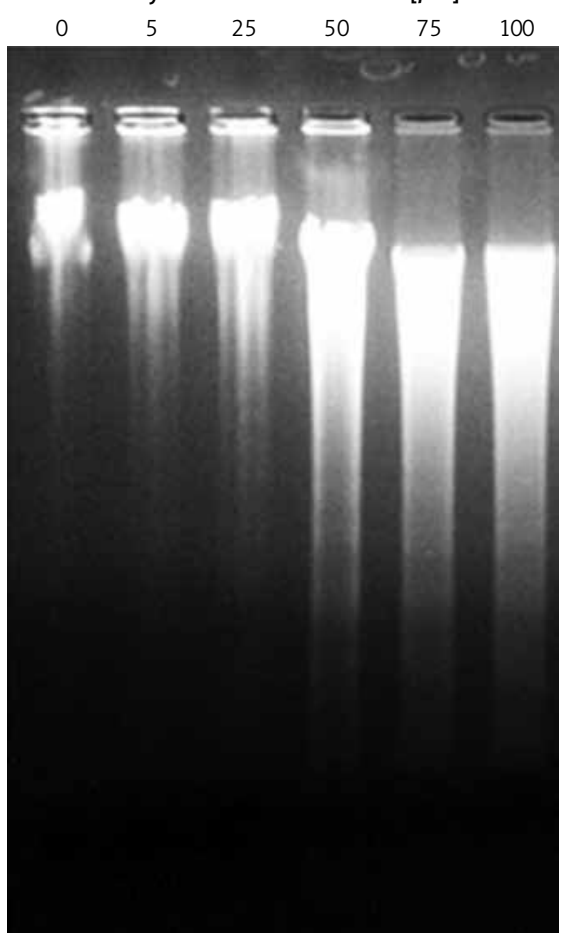

Figure 5. Dehydrocostus lactone induces DNA fragmentation in BON-1 human pancreatic neuroendocrine tumor cell lines. The cells were treated with $0,5,25,50,75$ and $100 \mu \mathrm{M}$ for $48 \mathrm{~h}$ and harvested and fragmented DNA was extracted and analyzed by $1.5 \%$ agarose gel electrophoresis
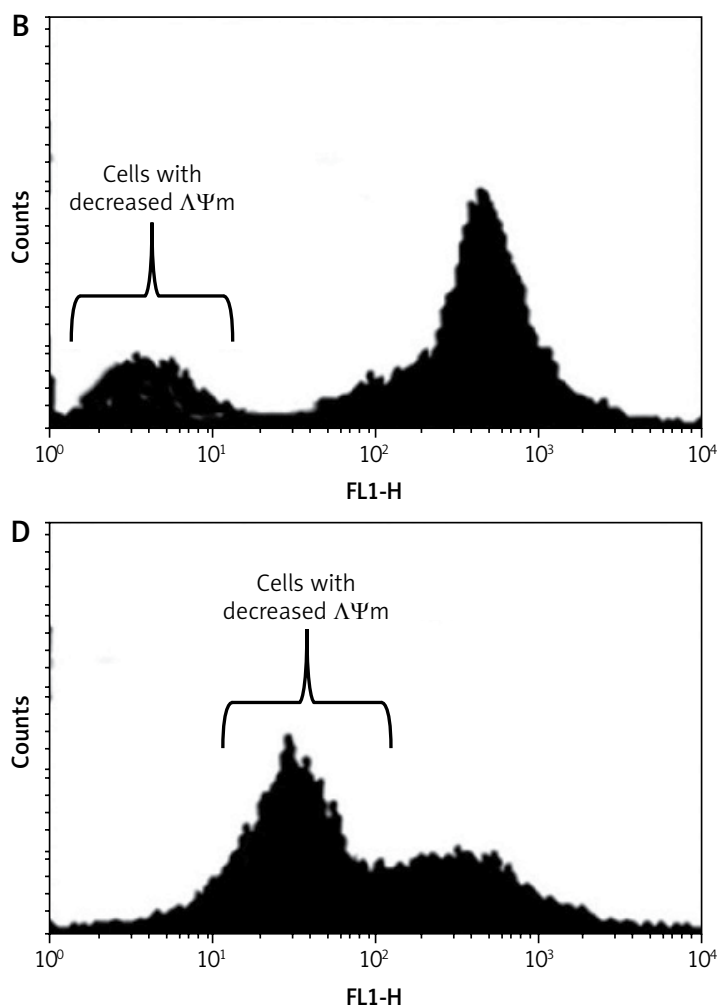

Figure 6. Measurement of the effects of dehydrocostus lactone on the mitochondrial membrane potential loss $(\Lambda \Psi \mathrm{m})$ in BON-1 cells using flow cytometry and Rh-123 as fluorescent probe. A - Untreated cells (control), while B-D - cells treated with 5,50 and $100 \mu \mathrm{M}$ doses of the compound. The percentage of cells with decreased $\Lambda \Psi \mathrm{m}$ increased from $3.58 \%$ in the control group to $14.2 \%, 24.6 \%$ and $43.3 \%$ in 5, 50 and $100 \mu \mathrm{M}$-dehydrocostus lactone treated cells respectively 

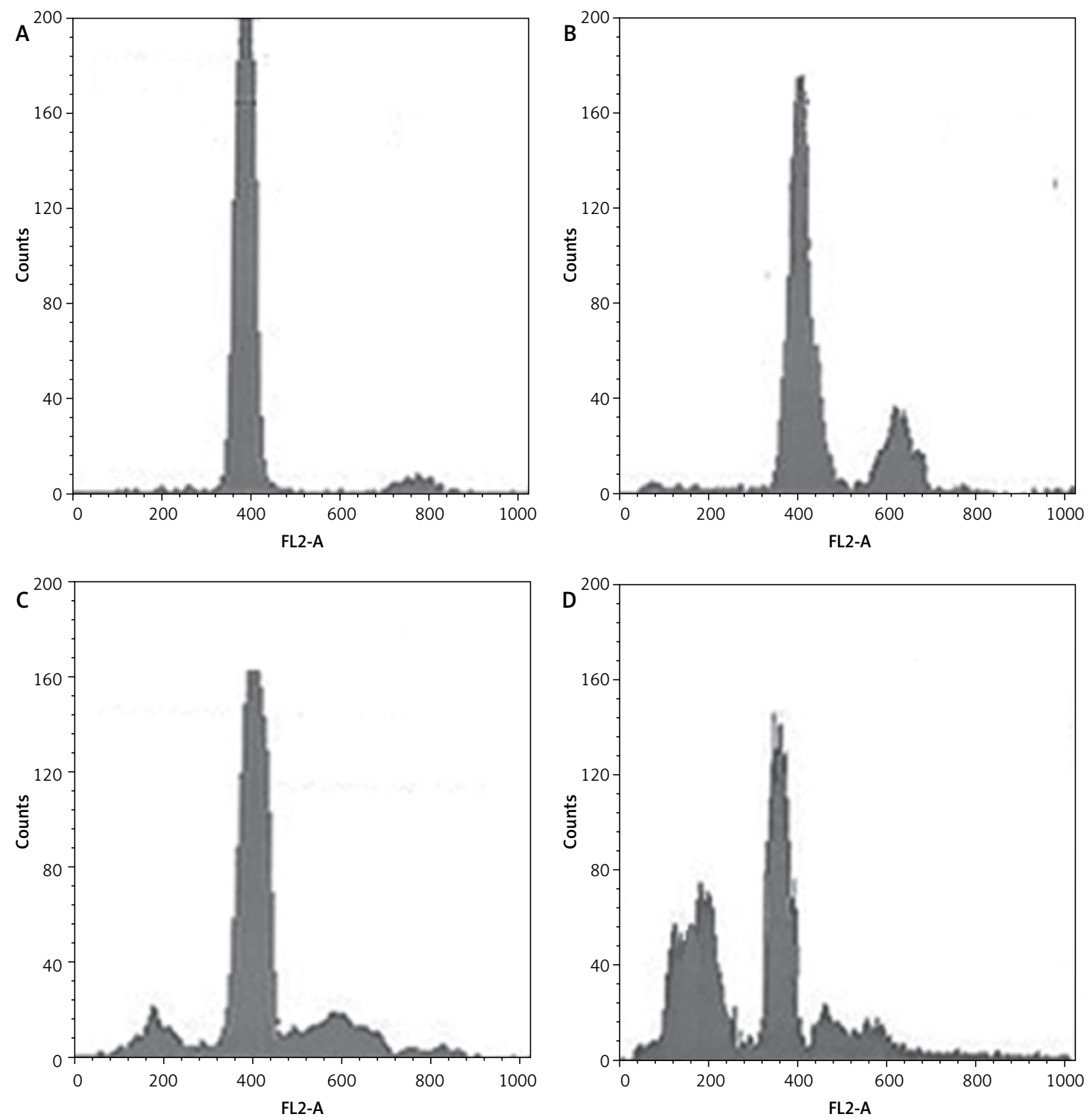

Figure 7. Dehydrocostus lactone induces sub-G1 cell cycle arrest in BON-1 cells. The cells were treated with different doses of dehydrocostus lactone $(0 \mu \mathrm{M}(\mathrm{A}), 5 \mu \mathrm{M}$ (B), $50 \mu \mathrm{M}$ (C) and $100 \mu \mathrm{M}(\mathrm{D}))$ and then analyzed by flow cytometry using propidium iodide as a probe. The flow cytometry images are representatives of three biological replicates

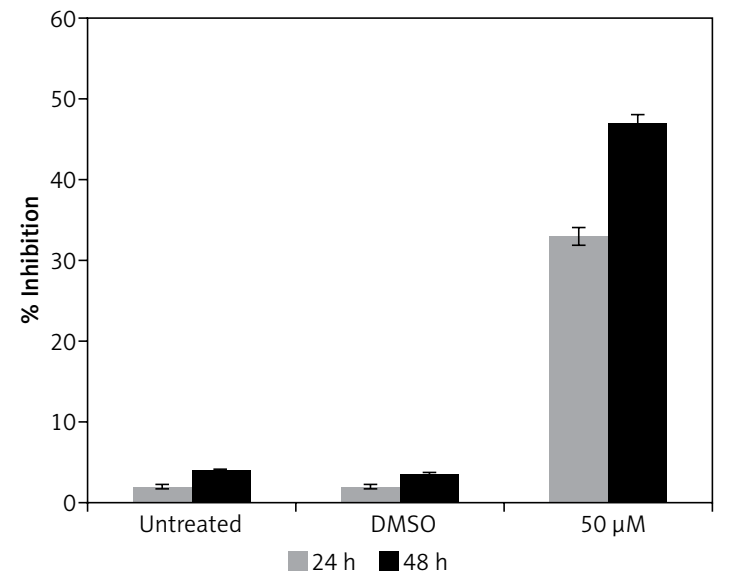

Figure 8. Effect of solvent DMSO on cell proliferation of BON-1 cells. The experiment was carried out in three biological replicates \pm SD
It has been reported that the process of cancer development is closely linked to the biochemical processes of cell cycle and apoptosis. Currently, the drug discovery process focuses on chemotherapeutic agents which can target the cell cycle and apoptosis [9-14].

Dehydrocostus lactone belongs to the sesquiterpene lactone class of naturally occurring compounds. They are sesquiterpenoids and contain a lactone ring. Sesquiterpene lactones are found in several plants and are well known for causing allergic reactions $[15,16]$. Dehydrocostus lactone along with costunolide has been reported to induce apoptosis and cell cycle arrest in human soft tissue sarcoma cells. Dehydrocostus lactone caused sub-G1 cell cycle arrest, as evident from the increased number of sub-G1 cells in the treated cells. A previous 
study reported that a similar type of compound causes G2/M cell cycle arrest [17, 18]. Moreover, the current study used a different and rare cancer cell line, viz. BON-1 (human pancreatic neuroendocrine tumor cell lines), which may be one reason for the cell cycle results reported in the present study. The findings of the present study report a different mechanism of action of dehydrocostus lactone. It induced sub-G1 cell cycle arrest and also induced loss of mitochondrial membrane potential, indicating the intrinsic apoptotic pathway.

In conclusion, the findings of the present study reveal that dehydrocostus lactone inhibited cancer cell growth in human pancreatic neuroendocrine tumor cell lines via the induction of mitochondrial mediated apoptosis, cell cycle arrest, DNA fragmentation and loss of mitochondrial membrane potential.

\section{Acknowledgments}

Hou-yong Long and Qing-xian Huang contributed equally to this work.

\section{Conflict of interest}

The authors declare no conflict of interest.

\section{References}

1. Schimmack S, Svejda B, Lawrence B, Kidd M, Modlin IM. The diversity and commonalities of gastroenteropancreatic neuroendocrine tumors. Langenbecks Arch Surg 2011; 396: 273-98.

2. Parekh D, Ishizuka J, Townsend CM Jr, et al. Characterization of a human pancreatic carcinoid in vitro: morphology, amine and peptide storage, and secretion. Pancreas 1994; 9: 83-90.

3. Yao JC, Hassan M, Phan A, et al. One hundred years after "carcinoid": epidemiology of and prognostic factors for neuroendocrine tumors in 35,825 cases in the United States. J Clin Oncol 2008; 26: 3063-72.

4. Kulke MH, Siu LL, Tepper JE, et al. Future directions in the treatment of neuroendocrine tumors: Consensus report of the National Cancer Institute Neuroendocrine Tumor clinical trials planning meeting. J Clin Oncol 2011; 29: 934-43.

5. Moertel C, Kvols L, O'Connell M, Rubin J. Treatment of neuroendocrine carcinomas with combined etoposide and cisplatin. Evidence of major therapeutic activity in the analplastic variants of these neoplasms. Cancer 1991; 68: 227-32.

6. Metz D, Jensen R. Gastrointestinal neuroendocrine tumors, pancreatic endocrine tumors. Gastroenterology 2008; 135: 1469-92.

7. Hung JY, Hsu YL, Ni WC, et al. Oxidative and endoplasmic reticulum stress signaling are involved in dehydrocostus lactone mediated apoptosis in human non-small cell lung cancer cells. Lung Cancer 2010; 68: 355-65.

8. Tabata K, Nishimura Y, Takeda T, Kurita M, Uchiyama T, Suzuki T. Sesquiterpene lactones derived from Saussurea lappa induce apoptosis and inhibit invasion and migration in neuroblastoma cells. J Pharmacol Sci 2015; 127: 397-403.
9. Kim EJ, Lim SS, Park SY, Shin HK, Kim JS, Park JH. Apoptosis of DU145 human prostate cancer cells induced by dehydrocostus lactone isolated from the root of Saussurea lappa. Food Chem Toxicol 2008; 46: 3651-8.

10. Kroemer G, Reed JC. Mitochondrial control of cell death. Nat Med 2000; 6: 513-9.

11. Elmore S. Apoptosis: a review of programmed cell death. Toxicol Pathol 2007; 35: 495-516.

12. Kerr JF, Wyllie AH, Currie AR. Apoptosis: a basic biological phenomenon with wide-ranging implications in tissue kinetics. Br J Cancer 1972; 26: 239-57.

13. Rather MA, Amin S. A comprehensive review on the phytochemical and pharmacological aspects of Podophyllum hexandrum: a high value medicinal plant. Adv Biomed Pharma 2016; 3: 216-26.

14. Banday JA, Shah SA, Kanth AH, Farozi A, Wani H. In vitro screening for anticancer activity of petroleum ether and ethyl acetate extracts of Conyza canedensis growing in Kashmir region. Adv Biomed Pharma 2015; 2: 82-5.

15. Nakagawa M, Ohno T, Maruyama R, et al. Sesquiterpene lactone suppresses vascular smooth muscle cell proliferation and migration via inhibition of cell cycle progression. Biol Pharm Bull 2007; 30: 1754-7.

16. Mohammadi-Motlagh HR, Mostafaie A, Mansouri K. Anticancer and anti-inflammatory activities of shallot. Arch Med Sci 2011; 7: 38-44.

17. Choi YK, Seo HS, Choi HS, et al. Induction of Fasmediated extrinsic apoptosis, p21WAF1-related G2/M cell cycle arrest and ROS generation by costunolide in estrogen receptor-negative breast cancer cells, MDA-MB-231. Mol Cell Biochem 2012; 363: 119e128.

18. Kretschmer N, Rinner B, Stuendl N, et al. Effect of costunolide and dehydrocostus lactone on cell cycle, apoptosis, and $A B C$ transporter expression in human soft tissue sarcoma cells. Planta Med 2012; 78: 1749-56. 